\title{
THE LEVEL OF NEIGHBORHOOD WALKABILITY IN A PLACE OF RESIDENCE AND ITS EFFECT ON BODY COMPOSITION IN OBESE AND OVERWEIGHT WOMEN
}

\author{
Tereza Sofková1, Miroslava Přidalová1, Josef Mitáš2, Jana Pelclová2 \\ 'Department of Natural Sciences in Kinanthropology, Faculty of Physical Culture, Palacký University Olomouc, Olomouc, Czech Republic \\ ${ }^{2}$ Institute of Active Lifestyle, Faculty of Physical Culture, Palacký University Olomouc, Olomouc, Czech Republic
}

\begin{abstract}
SUMMARY
A neighborhood environment allows defining typical features for physically active or inactive lifestyle. An accelerated pace of life and higher availability of an unhealthy lifestyle increase obesity rates. An analysis of body composition can be used as a predictor for assessment of current somatic conditions. The aim of the study was to determine the dependence of selected body composition parameters on neighborhood walkability in 167 women aged 20-60 years attending weight-loss programme called STOB-courses. A multifrequency bioimpedance analysis InBody 720 was used to determine the body composition of respondents. Further, ANEWS questionnaire was used to determine the level of neighborhood walkability. We divided the sample into two age groups ( $<40$ years; $\geq 40$ years) and into partial subgroups according to the neighborhood "level of walkability" (lower and higher level). Based on the assessment of body composition, it can be assumed more walkable neighborhood opportunities positively affect body composition. Body composition in older women is positively influenced if they lived in high walkable areas. In younger women we found only one indicator of body composition (body fat mass) influenced by neighborhood walkability. The relationship between health indicators of body composition and residential infrastructure might be useful in strategies aimed at maintaining and developing a healthy lifestyle within the community.
\end{abstract}

Key words: questionnaire ANEWS, environmental conditions, bioimpedance analysis, InBody 720, weight-loss programme

Address for correspondence: T. Sofková, Department of Natural Sciences in Kinanthropology, Faculty of Physical Culture, Palacký University, tř. Míru 115, 77141 Olomouc, Czech Republic. E-mail: tereza.sofkova@email.cz

\section{INTRODUCTION}

Sedentary behaviour and obesity issues are often discussed in relation to social health. Lack of regular physical activity is associated with increasing obesity and subsequent impact on human health. Sedentary behaviour is associated with health problems as well as with psychological and social risks (1). Decreasing level of physical activity is influenced by factors like obesity rate, smoking and educational level. Obese individuals, smokers and individuals with secondary or tertiary education demonstrate lower levels of physical activity (2). Ball et al. in their study found that in $6.2 \%$ of women being overweight and in $22.6 \%$ of obese women their status represents a barrier for them to be physically active (3). A number of overweight and obese people increases every year, therefore, it is necessary to search for ways how to promote at least general guidelines for physical activities $(4,5)$. Kwasniewska et al. support the need for implementing effective interventions in the society, especially in the area of weight reduction and increasing physical activity level (6). National obesity prevention programmes based on epidemiologic studies and monitoring of population health and health determinants should be developed (7).

Factors influencing lifestyle include the environment, physical activity behaviour, demographic factors, cultural differences, genetic, ethical, ethnic and political factors, etc. In Europe, there are prepared strategic documents supporting the physical activity promotion across Europe $(8,9)$. The purpose of these documents is to set out an integrated EU approach to contribute to reducing ill health due to poor nutrition, overweight and obesity. The problem of obesity in the Czech Republic prevails, since there is no document for strategic planning and promotion of physical activity and healthy lifestyle (10).

Government budget supports directly sport and physical activity professionals, however, less financial means are allocated to develop infrastructure that would promote sports in all strata population. In the past extensive construction of prefabricated block of flats built often in larger villages including less sensitive landscape modification activities resulted in a significant reduction of walking (11). Safe and accessible neighborhoods however positively affect the amount of walking (12). Walking in the Czech Republic is still the most natural and widespread physical activity as well as the most important component of overall physical activity (13-15). Walking has numerous potential benefits for population health in addition to preventing cardiovascular diseases and other risk behaviours (16).

High proportion of body fat is associated with obesity, which leads to health complications. This status may disadvantage these individuals in social and community living. Risk is defined by the level of body fat between $10-20 \%$ for men and $18-28 \%$ for 
women. Obesity is associated with orthopedic, cardiorespiratory and psychosocial disorders. The World Health Organization designated obesity as an epidemic of the 21 st century and included it among chronic non-infectious diseases that will exceed an estimated prevalence of $73 \%$ by 2020 . Obesity poses a major health risk and decreases quality and length of life. It is the second leading cause of death after smoking (17). Among main indirect epidemic obesity causes WHO includes increasing urbanization, industrialization and disappearance of traditional lifestyle; direct factors are then sedentary lifestyle and high-energy diet (18). To maintain desirable weight energy expenditure, Saris et al. recommend about $12 \mathrm{kcal} / \mathrm{kg}$ of body weight per day or at least 10,000 steps per day (5). More than half of the adult population in the Czech Republic is overweight or obese (19). The Czech Republic holds the 10th place on the European scale with $17 \%$ of obese individuals. This represents an increase of 3\% since 1999 (20).

Physical activity is an irreplaceable part of human life and thus is included in various intervention programmes. It is also used in weight loss programme - STOB courses, where cognitivebehavioural psychotherapy is recommended for clients as a part of their treatment. Changes in eating habits induced by the cognitive behavioural therapy along with regular physical activity help to promote successful long-term goal for weight-loss. This psychological method of treatment is based on the fact that inappropriate eating and exercise habits are learned and therefore can be changed. Psychotherapy and relaxation techniques in weight-loss programmes are also necessary for obese individuals to overcome negative emotions, stress, depression, and anxiety (21). An important component of weight loss programmes is promotion of physical activity as it relates to long-term maintenance of reduced weight and optimal functioning of individual body parts. It prevents reduction of basal metabolism and fat-free mass. Physical activity, one of the most important components of healthy lifestyle, is at weight-loss programme in Olomouc and its surroundings monitored by pedometers and accelerometers. Feedback at the amount of physical activity and an emphasis on its implementation is an important motivating factor for obese and overweight women $(22,23)$.

One of the key determinants of physically active behaviour is the neighborhood environment. Environmental impact on health and active lifestyle was recognized in theories of health behaviour changes (24). Walkability and access to destinations in neighborhood are often discussed topics within international research studies looking for associations between healthy indicators of urban residents. Therefore, searching for associations between body weight, lifestyle and physical activity especially in the group of overweight and obese females is needed.

\section{MATERIALS AND METHODS}

The examined sample consisted of 167 women aged 20-60 years, who went through a body composition testing using a multifrequency bioimpedance method. Their neighborhood environments were analyzed using the ANEWS questionnaire. The research part of the project was conducted in 2010 and 2011 during 9 courses of weight-loss programme.

Measurements of body composition and neighborhood environments were performed before the start of STOB course.
Courses are designed for weight loss, however, they are not directed only towards regular physical activity as a health-oriented component of a healthy lifestyle, but they also have a theoretical content, because weight loss is dependent mainly on adjusting habits regarding lifestyle and living, especially nutritional stereotypes and physical therapy (cognitive behavioural psychotherapy).

The multifunctional, multifrequency device InBody 720 (a method of directly-controlled segmental bioelectrical impedance) was used to diagnose body composition. The applied method is unified and the measurement was performed according to standards set in the manual of the device (25).

Optimal body composition is considered to be an adequate indicator of the functional state and physical prowess of an organism. Among health indicators of a body composition that determine obesity belong BMI, the amount of fat fraction (Body Fat Mass, $\mathrm{kg}, \%$ ), the amount of fat fraction in $\mathrm{kg}$ due to the square of height (Body Fat Mass Index, BFMI), visceral (internal) fat (VFA - visceral fat Area), and obesity degree.

Assessment of fat-free mass (FFM - Fat-Free Mass) is an important individual indicator of an adequately set physical activity prescription. Similarly to the previous parameter, it can be related to body height. The sum of BFMI and FFMI (Body Fat Mass Index, Fat-Free Mass Index) indicates the BMI (26). In addition, we focused on body water representation (TBW - Total Body Water) concentrated into two main body compartments - extracellular and intracellular (ECW - Extracellular Water, ICW - Intracellular Water). Additional parameter (FS - Fitness Score) is based on the representation of muscle and fat fraction of the individual.

Neighborhood environments were monitored using the ANEWS questionnaire (27). The questionnaire ANEWS (Neighborhood Environment Walkability Scale - Abbreviated) used in the Czech Republic is based on recommendations from the IPEN (International Physical Activity and the Environment Network) research grant "IPEN: International Study of Built Environment, Physical Activity and Obesity." A subjective evaluation of environmental conditions describes the place based on its level of walkability and the evaluation is determined according to the score in a particular section of the questionnaire. Walkability represents opportunities to be physically active close to one's home. Environmental conditions are characterized within the questionnaire by residential density and diversity of the land use characterizing availability to visit selected services and facilities within a certain time interval. Further observed variables of walkability within the ANEWS questionnaire are street connectivity, cycling and walking facilities, neighborhood aesthetics, and residential safety.

\section{Statistical Analysis}

Descriptive statistics and data analysis were performed using the statistical program Statistica 10.0 (28). Participants were divided into two groups according to age ( $<40$ and $\geq 40$ years). Based on the questionnaire scores of walkability, two groups of women were created (higher or lower walkability). Using cluster analysis $\mathrm{K}$-means and based on parameters DE - main walkability factors ( $\mathrm{GH}$ - motivational walkability factors, $\mathrm{COMP}$ - comprehensive walkability factors) we created groups, which are characterized by a higher or lower walkability (27). We used student's unpaired t-test to compare individual groups, the two-factor analysis of vari- 
ance to monitor the effects of two factors (age and walkability), and Scheffe post hoc test to compare two groups.

\section{RESULTS AND DISCUSSION}

First, we focused on fractionation of body composition in women regardless of their residence and neighborhood. Selected somatic characteristics of the observed group of women (Table 1) were differentiated according to age. Although monitored parameters are almost homogeneous for both groups, older women had significantly higher values of visceral fat exceeding recommended values (Visceral Fat Area $>100 \mathrm{~cm}^{2}$ ) compared to younger women (younger women: $\mathrm{VFA}=124.75 \mathrm{~cm}^{2}$; older women: $\mathrm{VFA}=154.84$ $\left.\mathrm{cm}^{2} ; \mathrm{p}<0.001\right)$. Distribution of body fat is determined genetically and partially hormonally regulated, that is why we can follow its redistribution from periphery into abdomen in postmenopausal women (29). Higher values of visceral fat determine abdominal obesity, which is one of the main criteria for metabolic syndrome assessment, and have almost comparable predictive value for severe cardiovascular diseases (30). Body mass index was in a range of obesity for both age groups (younger women: BMI=30.76; older women: $\mathrm{BMI}=31.76$ ). $\mathrm{BMI}$ does not capture variability and changes in the representation of body fat and fat-free mass. In order to obtain more objective assessment of relative risks of health problems, we used for example the body fat mass index (BFMI) and fat-free mass index (FFMI). Classification for BMI $>30 \mathrm{~kg}$ / $\mathrm{m}^{2}$ is set at BFMI $\geq 11.8$ and at FFMI $\geq 18.2$, which corresponds to our results (26). Fat is the most variable component of body weight - a major factor in inter- and intra-individual variability in body composition that is easily influenced by developmental aspects and physical activity (31). Based on the average values of percentages of fat fraction by Heyward and Wagner (32), both age groups of women were classified as obese $(>35 \%)$. We recorded relatively higher proportion of fat (higher by $1.83 \%$ ) in older women. The increase of body fat is related to increasing age as confirmed in a study by Kyle et al. (33). In addition, Guo et al. (34) found that total amount of body fat in adulthood increases by about $0.37 \mathrm{~kg}$ per year in men and $0.41 \mathrm{~kg}$ in women. Rokyta (35) indicates the content of water in adipose tissue to be only $10 \%$. Water content is therefore low in obese people, as it constitutes only $45 \%$ of body weight. Total body water in young women from our sample made up $43.5 \%$ and in older women $42.4 \%$. Gába and Přidalová (36), similarly to Přidalová et al. (22) emphasized a decrease in total body water (TBW), which is primarily caused by an intracellular water reduction depending on increasing age. Differences of intracellular water (ICW) were only minimal in observed samples. Intracellular water (ICW) ideally comprises approximately $65 \%$ of total body water, while remaining $35 \%$ comprises extracellular water $(\mathrm{ECW})$. This ratio is about 62.0:38.0 for younger women and 61.7:38.3 for older women.

Questionnaires were used to define general characteristics of neighborhood walkability according to residential density, land use mix, street connectivity, availability of facilities and services, and infrastructure and safety.

Based on walkability assessment we can classify the selected sample as homogenous in relation to frequency at different ages. Key factors such as the ability to walk to selected services and facilities within a certain time interval in terms of frequency are balanced for both age groups.

The first part of the questionnaire examines types of residences within the neighborhood. The level of walkability created from this part showed that there was no significant difference found between individual fractions of body composition for both age groups. Walkability level is higher for a larger number of households in a small area with connections to infrastructure of services and lower in an area of family houses. Results show that fat fraction is most frequently affected by the level of walkability

Table 1. Basic characteristics of sample in relation to age

\begin{tabular}{|c|c|c|c|c|c|}
\hline \multirow{2}{*}{ Parameter } & \multicolumn{2}{|c|}{$<40$ years; $n=80$} & \multicolumn{2}{|c|}{$\geq 40$ years; $n=87$} & \multirow{2}{*}{$\mathrm{p}$} \\
\hline & Mean & SD & Mean & SD & \\
\hline Age & 31.28 & 5.86 & 50.29 & 6.67 & $<0.01$ \\
\hline Height (cm) & 166.95 & 7.18 & 164.71 & 7.44 & 0.06 \\
\hline Weight (kg) & 85.62 & 16.33 & 86.09 & 13.37 & 0.83 \\
\hline BMI $\left(\mathrm{kg} / \mathrm{m}^{2}\right)$ & 30.76 & 5.75 & 31.76 & 4.62 & 0.21 \\
\hline Fat fraction (\%) & 39.73 & 6.59 & 41.56 & 6.06 & 0.06 \\
\hline Fat fraction $(\mathrm{kg})$ & 34.75 & 11.83 & 36.25 & 9.75 & 0.36 \\
\hline Index BFM (kg/m²) & 12.52 & 4.32 & 13.43 & 3.71 & 0.14 \\
\hline Visceral fat $\left(\mathrm{cm}^{2}\right)$ & 124.75 & 43.77 & 154.84 & 36.57 & $<0.01$ \\
\hline Fat-free mass (kg) & 50.86 & 6.39 & 49.83 & 6.16 & 0.29 \\
\hline Index FFM (kg/m²) & 18.23 & 1.84 & 18.32 & 1.43 & 0.72 \\
\hline Total body water (I) & 37.23 & 4.72 & 36.54 & 4.49 & 0.33 \\
\hline Extracellular water (I) & 14.13 & 1.84 & 13.97 & 1.72 & 0.54 \\
\hline Intracellular water (I) & 23.09 & 2.90 & 22.56 & 2.79 & 0.23 \\
\hline Edema 1 & 0.33 & 0.00 & 0.34 & 0.00 & $<0.01$ \\
\hline Edema 2 & 0.37 & 0.00 & 0.38 & 0.00 & $<0.01$ \\
\hline Fitness score & 65.22 & 8.64 & 63.86 & 9.12 & 0.32 \\
\hline
\end{tabular}


in neighborhood by residential density characterized according to type of residences. Average values of absolute fat fraction values are lower in both age groups of women living in homes with higher walkability regarding the type of housing. Mitas (10) reported that neighborhood residential density is not a separate factor that would stimulate walking for transportation. It is rather higher residential density that is associated with greater use of local infrastructure.

The second part of the questionnaire focuses on the availability of different types of infrastructures within the walking distance of residence (shops, services, schools, recreational centers). Land use mix and walking distance of facilities belong among the most important factors affecting the walking within neighborhood (27). Frank et al. (37) found that the land use mix has a significant impact on obesity in population. If a person lives in an area with higher walkability, he/she is able to walk about one kilometer more easily than those living in low walkable area. Walking one more kilometer may lower the risk of obesity by $4.8 \%$. Our sample indicates noticeable differences in mean values of fat fraction $(\%)$ in younger women among the groups divided by the degree of walkability.

The third part of the questionnaire examines availability of services that are within walking distance near a place of residence. It is an adjunctive characteristic describing the diversity of land use. An independently evaluated factor of access to services associated with environmental barriers does not show significant difference in observed fractions of body composition with respect to the level of walkability.

The fourth part of the questionnaire examines neighborhood characteristics in terms of road network. We did not find any significant relationships among street connectivity with regards to the fraction of body composition in groups divided according to the degrees of walkability.

The fifth part of the survey describes the place of residence in terms of conditions suitable for active transportation (walking and cycling). If we characterize these conditions as environments with higher or lower level of walkability, we observe significant differences in the group of older women in fat-free mass (FFM: $\mathrm{p}=0.03$ ), total body water (TBW: $\mathrm{p}=0.03$ ), and intracellular (ICW: $\mathrm{p}=0.02)$ and extracellular water $(\mathrm{ECW}: \mathrm{p}=0.03)$. The group of older women with higher level of walkability had significantly lower fat-free mass and body water.

Another part of the questionnaire monitors the neighborhood attractiveness which can motivate people to achieve higher levels of overall walking. Based on housing in an attractive environ- ment, we do not observe any significant differences in fractions of body composition.

The last part of the questionnaire examines safety. There is a small effect of walkability on fractions of body composition in terms of traffic safety and crime in residential neighborhoods. In general, people spend significantly smaller amount of time engaged in leisure-time physical activities in their neighborhood, if they do not feel safe there $(38,39)$. Results of our study show that residential safety in regards to walkability has little influence on absolute and relative representation of fat fraction in older women.

The combined score of all factors evaluating the overall level of neighborhood walkability indicates walking availability of a particular place and its relationship to body composition of women living there. As expected, women living in high walkable areas exhibit less health risks in terms of body composition. The younger group of women living in areas with higher walkability has slightly lower values of visceral fat, relative and absolute value of body fat and fat-free mass.

Neither the level of walkability in individual survey items (ANEWS) nor the comprehensive factor of walkability from all areas of the questionnaire significantly affected fractions of body composition. A conjunction of the second and the third part of the questionnaire representing crucial factors regarding walkability has an interesting effect on body composition as well as a conjunction of the fifth and the sixth part of the questionnaire that can serve as an evaluation of the degree of walkability in relation to motivation (Table 2).

A combined score of the second and third part of the questionnaire focused on the walking distance to different types of infrastructure and facilities - crucial factors regarding walkability (Table 3). The group of younger women with higher level of walkability had significantly lower body fat (PBF: $p=0.01)$. Figure 1 allowed us to assess relative differences of average relative body fat values and $95 \%$ confidence intervals for women, whose residence belonged among residences with higher or lower walkability conditions. Women of various age living in a neighborhood with lower walkability had very similar values of relative body fat.

If we merge the score of the fifth and the sixth part of the questionnaire, we evaluate it in terms of the level of walkability as motivational factors (Table 3). The influence of walkability in terms of motivation is significantly different only in older women regarding total body water (TBW: $\mathrm{p}=0.01$ ) and associated intracellular (ICW: $\mathrm{p}=0.02)$ and extracellular water (ECW: $\mathrm{p}=0.01)$. A significant difference was found also for fat-free mass (FFM: $p=0.01$ ). Interesting results were found for visceral fat

Table 2. Average values of selected parameters in relation to higher/lower level of merged walkability categories

\begin{tabular}{|l|c|c|c|c|}
\hline \multirow{2}{*}{ Section in residential neighborhood } & \multicolumn{2}{|c|}{$<40$ years; $n=80$} & \multicolumn{2}{c|}{$\geq 40$ years; $\mathbf{8 0 7}$} \\
\cline { 2 - 5 } & Lower walkability & Higher walkability & Lower walkability & Higher walkability \\
\hline Types of home & 39 & 41 & 46 & 41 \\
\hline Shops, facilities (D) & 39 & 41 & 40 & 47 \\
\hline Access to services (E) & 1 & 79 & 6 & 81 \\
\hline Streets & 2 & 78 & 16 & 71 \\
\hline Places for walking and biking (G) & 9 & 71 & 18 & 69 \\
\hline Surroundings (H) & 15 & 65 & 15 & 72 \\
\hline Safety & 43 & 37 & 46 & 41 \\
\hline
\end{tabular}


Table 3. Average values of selected somatic parameters in relation to a higher/lower level of merged walkability categories

\begin{tabular}{|c|c|c|c|c|c|c|}
\hline \multirow{2}{*}{ Parameter } & \multicolumn{3}{|c|}{$<40$ years; $n=80$} & \multicolumn{3}{|c|}{$\geq 40$ years; $n=87$} \\
\hline & Mean/DE & Mean/GH & Mean/COMP & Mean/DE & Mean/GH & Mean/COMP \\
\hline BMI $\left(\mathrm{kg} / \mathrm{m}^{2}\right)_{-} \mathrm{H}$ & 29.92 & 30.28 & 30.31 & 31.97 & 31.38 & 31.49 \\
\hline BMI $\left(\mathrm{kg} / \mathrm{m}^{2}\right) \_\mathrm{L}$ & 31.44 & 31.63 & 30.96 & 31.55 & 32.32 & 31.88 \\
\hline Fat fraction (\%)_H & 37.70 & 39.44 & 38.61 & 41.86 & 41.66 & 41.26 \\
\hline Fat fraction (\%)_L & 41.38 & 40.17 & 40.23 & 41.27 & 41.39 & 41.69 \\
\hline Index BFM $\left(\mathrm{kg} / \mathrm{m}^{2}\right) \_\mathrm{H}$ & 11.60 & 12.17 & 12.04 & 13.60 & 13.27 & 13.21 \\
\hline Index BFM $\left(\mathrm{kg} / \mathrm{m}^{2}\right) \_\mathrm{L}$ & 13.28 & 13.08 & 12.74 & 13.27 & 13.67 & 13.53 \\
\hline Visceral fat $\left(\mathrm{cm}^{2}\right) \_\mathrm{H}$ & 120.73 & 121.70 & 121.83 & 155.46 & 150.98 & 153.58 \\
\hline Visceral fat $\left(\mathrm{cm}^{2}\right) \_\mathrm{L}$ & 128.04 & 129.56 & 126.08 & 154.26 & 160.57 & 155.40 \\
\hline Index FFM $\left(\mathrm{kg} / \mathrm{m}^{2}\right)_{-} \mathrm{H}$ & 18.31 & 18.03 & 18.26 & 18.37 & 18.10 & 18.28 \\
\hline Index FFM $\left(\mathrm{kg} / \mathrm{m}^{2}\right) \_\mathrm{L}$ & 18.16 & 18.54 & 18.21 & 18.27 & 18.64 & 18.34 \\
\hline Total body water (I)_H & 38.11 & 36.71 & 38.17 & 36.49 & $35.35+$ & 36.49 \\
\hline Total body water $(I) \_L$ & 36.51 & 38.05 & 36.80 & 36.58 & $38.30+$ & 36.58 \\
\hline Extracellular water (I)_H & 14.46 & 13.95 & 14.48 & 13.98 & $13.50+$ & 13.87 \\
\hline Extracellular water (I)_L & 13.87 & 14.43 & 13.98 & 13.96 & $14.67+$ & 14.01 \\
\hline Intracellular water (I)_H & 23.64 & 22.76 & 23.68 & 22.50 & $21.85+$ & 22.56 \\
\hline Intracellular water (I)_L & 22.64 & 23.62 & 22.82 & 22.63 & $23.63+$ & 22.57 \\
\hline
\end{tabular}

$\mathrm{H} / \mathrm{L}$ - average parameter value in a higher/lower level of walkability, DE - main walkability factors, GH - motivational walkability factors , COMP - comprehensive walkability factors

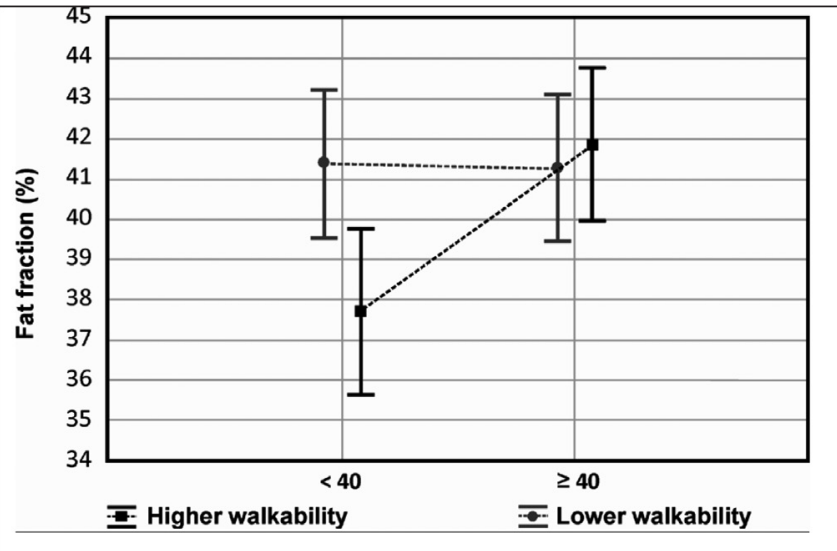

Fig. 1. Average relative values of body fat and $95 \%$ confidence intervals within higher/lower levels of walkability in terms of services availability.

with values that are significantly different for various ages (VFA $=0.02$ ). Average values of VFA and $95 \%$ confidence intervals are lower for both groups of women living in areas with higher walkability (Fig. 2).

\section{CONCLUSION}

The neighborhood walkability level in terms of providing individuals with easy access to shops, services and facilities was similar for both age groups. This applies to a close neighborhood, which is well arranged in terms of services and safety accessible by walking or cycling. During the establishment of the relationship between fractions of body composition and parameters monitored in the questionnaire, it was found that more walkable environment

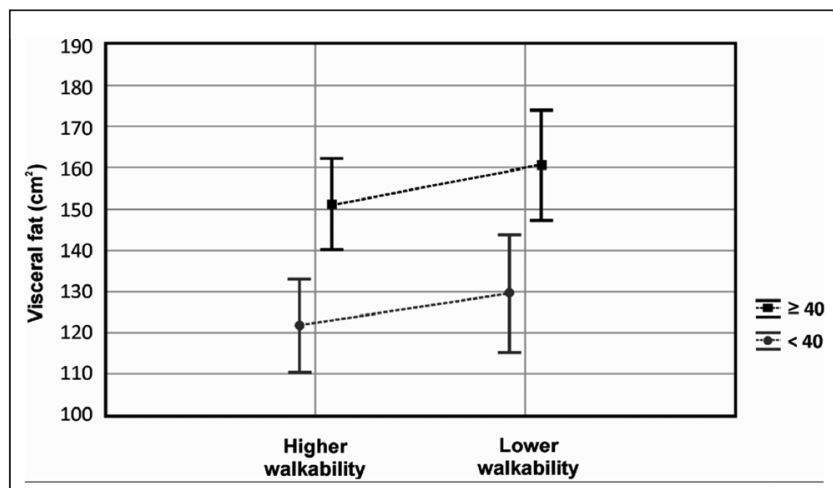

Fig. 2. Mean values and $95 \%$ confidence intervals of visceral fat in relation to higher/lower degree of walkability according to motivation to physical activity implementation.

is positively reflected in older women with regards to fractions of body composition. In younger women we found that only body fat mass was influenced by neighborhood walkability.

A most recent research topic is to promote healthy lifestyles through physical activity within the neighborhood environment. As shown in our study, positive changes in infrastructure focused on promotion of health and healthy lifestyle can lead to reduction of health problems associated with obesity.

\section{Acknowledgements}

The study was conducted within the framework of research project "Physical activity and inactivity of inhabitants of the Czech Republic in context of behavioral changes" (MSM 6198959221) and IGA UP (FTK_2012_030): "The relationship between health indicators and physical activity in overweight and obese women". 


\section{REFERENCES}

1. Kalvach Z, Zadák Z, Jirák R, Zavázalová $H$, Sucharda $P$, et al. Geriatrics and gerontology. Prague: Grada; 2004. (In Czech.)

2. Norman A, Bellocco R, Vaida F, Wolk A. Total physical activity in relation to age, body mass, health and other factors in a cohort of Swedish men. Int J Obes Relat Metab Disord. 2002 May;26(5):670-5.

3. Ball K, Crawford D, Owen N. Too fat to exercise? Obesity as a barrier to physical activity. Aust N Z J Public Health. 2000 Jun;24(3):331-3.

4. Gába A, Přidalová M, Pelclová J, Riegerová J, Tlučáková L. Analysis of body composition and physical activity in Czech and Slovak women. Med Sport Bohem Slov. 2010;19(3):152-9. (In Czech.)

5. Saris WHM, Blair SN, van Baak MA, Eaton SB, Davies PSW, Di Pietro $\mathrm{L}$, et al. How much physical activity is enough to prevent unhealthy weight gain? Outcome of the IASO 1st Stock Conference and consensus statement. Obes Rev. 2003 May;4(2):101-14.

6. Kwaśniewska M, Kaleta D, Dziankowska-Zaborszczyk E, Drygas W Healthy behaviours, lifestyle patterns and sociodemographic determinants of the metabolic syndrome. Cent Eur J Public Health. 2009 Mar;17(1):149.

7. Tekkel M, Veideman T, Rahu M. Changes over fourteen years in adult obesity in Estonia: socioeconomic status and use of outpatient health services. Cent Eur J Public Health. 2010 Dec;18(4):186-91.

8. Commission of the European Communities. White paper: white paper on sport [Internet]. Brussels: Commission of the European Communities; 2007 [cited 2012 Apr 2]. Available from: http://ec.europa.eu/sport/ documents/wp_on_sport_en.pdf.

9. Commission of the European Communities. White paper on a strategy for Europe on nutrition, overweight and obesity related health issues [Internet]. Brussels: Commission of the European Communities; 2007 [cited 2012 Apr 2]. Available from: http://eur-lex.europa.eu/LexUriServ/ LexUriServ.do?uri=COM:2007:0279:FIN:EN:PDF.

10. Mitas J. Physical activity and environment in lifestyle of Czech residents. Olomouc: Palacky University; 2011. (In Czech.)

11. Czech Statistical Office. Statistical yearbook of the Czech Republic 2010 [Internet]. Prague: Czech Statistical Office; 2010 [cited 2011 Sep 23]. Available from: http://www.czso.cz/csu/2010edicniplan.nsf/engp/000110 .

12. Sigmund E, Mitáš J, Vašíčková J, Sigmundová D, Chmelík F, Frömel K, et al. Biosocial variables of physical activity in adults in selected cities in the Czech Republic. Ces Kinantropol. 2008;12(4):9-20. (In Czech.)

13. Frömel K, Bláha L, Dvořáková H, Feltlová D, Gajda V, Hájek J, et al. Physical activity of men and women 18 to 55 years old in Czech Republic. In: Vaverka F, editor. Movement and health: 3rd international conference: proceedings; 2003 Nov 21-22; Olomouc, Czech Republic. Olomouc: Palacky University; 2004. p. 169-73.

14. Frömel K, Mitáš J, Kerr J. The associations between active lifestyle, the size of a community and SES of the adult population in the Czech Republic. Health Place. 2009 Jun;15(2):447-54.

15. Mitáš J, Frömel K. Physical activity of adult population in the Czech Republic: overview of basic indicators for 2005 - 2009. Tel Kult. 2011; 34(1):9-21. (In Czech.)

16. Obesity: preventing and managing the global epidemic. Report of a WHO consultation. World Health Organ Tech Rep Ser. 2000;894:i-xii, 1-253.

17. Svačina Š S. Obesity and cardiovascular disease. Kapitoly Kardiol Lek Praxi. 2002;4(2):42-5. (In Czech.)

18. World Health Organization. Global strategy on diet, physical activity and health. Geneva: WHO; 2004

19. Láchová J, Daňková Š. European Health Interview Survey in CR - EHIS CR: Body Mass Index, physical activity, consumption of fruits and vegetables. Aktuální informace ÚZIS ČR [Internet]. 2010 [cited 2011 Sep 25];(70):1-11. Available from: http://www.uzis.cz/system/files/70_10. pdf. (In Czech.)
20. Organization for Economic Co-operation and Development. Health at a glance: Europe 2010. Paris: OECD; 2010.

21. Málkova I. Reasonable, healthy and permanent loss of weight. Prague: Smart Press; 2005. (In Czech.)

22. Přidalová M, Sofková T, Dostálová I, Gába A. Selected health indicators in women with overweight and obesity at the age of 20-60 years. Ces Antropol. 2011;61(1):32-8. (In Czech.)

23. Sofková T, Přidalová M, Pelclová J, Dostálová I. Changes in fat fraction in obese women in relation to recommended physical activity. Ces Antropol. 2011;61(1):39-44. (In Czech.)

24. Sallis JF, Cervero RB, Ascher W, Henderson KA, Kraft MK, Kerr J. An ecological approach to creating active living communities. Annu Rev Public Health. 2006;27:297-322.

25. Biospace. InBody 720 - the precision body composition analyzer [Internet]. Kroměříž: Biospace [cited 2010 Sep 3]. Available from: http://www. inbody.cz/soubory/katalogy-pdf/inbody720-cz-katalog.pdf. (In Czech.)

26. Kyle UG, Morabia A, Schutz Y, Pichard C. Sedentarism affects body fat mass index and fat-free mass index in adults aged 18 to 98 years. Nutrition. 2004 Mar;20(3):255-60.

27. Cerin E, Saelens BE, Sallis JF, Frank LD. Neighborhood Environment Walkability Scale: validity and development of a short form. Med Sci Sports Exerc. 2006 Sep;38(9):1682-91.

28. StatSoft. Statistica (data analysis software system) [Internet]. Version 10 Tulsa: StatSoft; 2011 [cited 2012 Feb 3]. Available from: http://www. statsoft.com

29. Toth MJ, Tchernof A, Sites CK, Poehlman ET. Effect of menopausal status on body composition and abdominal fat distribution. Int J Obes Relat Metab Disord. 2000 Feb;24(2):226-31.

30. Dukát A, Lietava J, Krahulec B, Čaprnda M, Vacula I, Sirotiaková J, et al. Prevalence of abdominal obesity in Slovakia. IDEA Study Slovakia. Vnitr Lek. 2007;53(4):326-30. (In Slovak.)

31. Riegerová J, Prridalová M, Ulbrichová M. Application of physical anthropology in physical education and sports. Olomouc: Hanex; 2006. (In Czech.)

32. Heyward VH, Wagner DR. Applied body composition assessment. Champaign, IL: Human Kinetics; 2004.

33. Kyle UG, Genton L, Slosman DO, Pichard C. Fat-free and fat mass percentiles in 5225 healthy subjects aged 15 to 98 years. Nutrition. 2001 Jul-Aug;17(7-8):534-41.

34. Guo SS, Zeller C, Chumlea WC, Siervogel RM. Aging, body composition, and lifestyle: the Fels Longitudinal Study. Am J Clin Nutr. 1999 Sep;70(3):405-11.

35. Rokyta R. Physiology: for bachelor's studies of medicine, sciences and physical education. Prague: ISV; 2000. (In Czech.)

36. Gába A, Přidalová M. Age-related changes in body composition in a sample of Czech women aged 18-89 years: a cross-sectional study. European Journal of Nutrition [Internet]. 2013 Apr [cited 2012 Aug 8]; doi: 10.1007/s00394-013-0514-x. Available from: http://link.springer.com/ article/10.1007\%2Fs00394-013-0514-x.

37. Frank LD, Andresen MA, Schmid TL. Obesity relationships with community design, physical activity, and time spent in cars. Am J Prev Med. 2004 Aug;27(2):87-96.

38. Bennett GG, McNeill LH, Wolin KY, Duncan DT, Puleo E, Emmons KM. Safe to walk? Neighborhood safety and physical activity among public housing residents. PLoS Med. 2007 Oct;4(10):1599-606.

39. Saelens BE, Handy SL. Built environment correlates of walking: a review. Med Sci Sports Exerc. 2008 Jul;40(7 Suppl):S550-66.

Received October 29, 2012

Accepted in revised form September 26, 2013 